\title{
Measuring Internet Diffusion in Italy
}

\author{
Andrea Bonaccorsi, Cristina Rossi \\ Sant'Anna School of Advances Studies, Pisa, Italy \\ bonaccorsi@sssup.it
}

\author{
Arianna Del Soldato, Maurizio Martinelli, Irma Serrecchia \\ Institute for Informatics and Telematics-CNR, Pisa, Italy \\ irma.serrechia@iit.cnr.it, maurizio.martinelli@iit.cnr.it, arianna.delsolato@iit.cnr.it
}

\begin{abstract}
The last 10 years witnessed an exponential growth of the Internet. According to Hobbes' Internet Timeline ${ }^{l}$, the Internet hosts are about 93 million, while in 1989 they were 100,000 . The same happens for second level domain names. In July 1989 the registered domains were about 3,900 while they were over 2 million in July 2000.This paper reports about the construction of a database containing daily observations on registrations of second level domain names underneath the "it" ccTLD ${ }^{2}$ in order to analyse the diffusion of Internet among families and businesses. The section of the database referring to domains registered by individuals is analysed. The penetration rate over the relevant population of potential adopters is computed at highly disaggregated geographical level (province). A concentration analysis is carried out to investigate whether the geographical distribution of Internet is less concentrated than population and income suggesting a diffusive effect. Regression analysis is carried out using demographic, social, economic and infrastructure indicators. Finally we briefly describe the further developments of our research. At the present we are constructing a database containing domains registered by firms together with data about the registrants; the idea is to use this new database and the previous one in order to check for the existence of power laws both in the number of domains registered in each province and in the number of domains registered by each firm.
\end{abstract}

Keywords: Domain names, Internet metrics, Diffusion, Power laws, Zipf's law

\footnotetext{
${ }^{1}$ URL: http://www.zakon.org/robert/internet/timeline/.

2 TLD is the acronyms of Top Level Domain. A top-level domain name can either be an ISO country code (for example .be stands for Belgium) or one of the generic top-level domains (a so-called gTLD such as .com, .org, .net and so on). To register a second level domain name (e.g. oecd.org) a user needs to apply to the domain name registry with the delegated authority for the ccTLD or gTLD. (OECD, 1998).
}

The original version of this chapter was revised: The copyright line was incorrect. This has been corrected. The Erratum to this chapter is available at DOI: 10.1007/978-0-387-35616-7_23 


\section{INTRODUCTION}

The Internet is getting bigger, and it's happening very fast, but very different figures are circulating about the extent of this phenomenon. One of the most cited results is that Internet traffic is doubling each three or four months displaying a sort of Moore's law for data traffic. This statement, which was true for the period 1995-1996, is no longer acceptable: it would have produced absurd traffic volumes (Coffman and Odlyzko, 2001).

The main difficulty in measuring the Internet is its distributed nature: it has no central authority in control and no directory of users exists. Moreover, it is not possible to give an unambiguous definition of an Internet user. A lot of different definitions are present in literature dealing with the time spent on line (Federcomin, 2000), the age of the users, the kind of activity performed (e-mail, surfing the Web, ftp and so on). In order to overcome this problem, several Internet metrics are available. The most suitable are the so-called endogenous metrics that are "obtained in an automatic or semiautomatic way from the Internet itself" (Diaz-Picazo, 1999). These metrics have the unquestionable advantage of the accuracy and among them the most used in the literature are Internet hosts and second level domain names (Naldi, 1997; Zook, 1999; Bauer, Berneand and Maitland, 2002). The widespread utilisation of Internet hosts is probably due to the easiness in obtaining data. The organisations that manage the different ccTLD and gTLD, perform the hostcount ${ }^{3}$ under their TLD on a regular basis and provide these data on the Web or by ftp. For instance every six months Network Wizard publishes the results about all the TLD on its web site ${ }^{4}$, whereas the RIPE ${ }^{5}$ publishes the data about the ccTLD in its area (Europe, North Africa, Middle East) monthly.

However, Internet hosts both under and over estimates the diffusion (Naldi, 1997). The under-estimation is due to the growing presence of firewalls and private networks (Intranet) together with the use of dynamic IP addresses for dial up accesses. Among factors of over-estimation the most important is the association multiple IP addresses to the same computer.

Among endogenous metrics, second level domain names represent a valid alternative to Internet hosts. This metric underestimate Internet diffusion: not all the users register a domain, nevertheless domains identify a lower bound in diffusion mainly capturing the proactive and interacting use of the network.

\footnotetext{
${ }^{3}$ For a definition of hostcount see OECD, 1998.

${ }^{4}$ URL: http://www.nw.com.

${ }^{5}$ URL: http://www.ripe.net/statistics/hostcoutn.htlm.
} 


\section{METHODOLOGY}

In July 2001, the Italian Registration Authority (RA) for the ccTLD "it"6 and the Sant'Anna School of Advanced Studies started a project for analysing the diffusion of the Internet network in Italy using domains registered underneath the ccTLD "it".

Data were extracted from the databases of the registrations managed by the $\mathrm{RA}^{7}$. As a first step, registrants are grouped into several categories (individuals, firms ${ }^{8}$, Universities and research centres, local public bodies, other public bodies and other registrants) in order to determine, for each category, the determinants of adoption and then of diffusion. A careful work of data cleaning was undertaken.

At the present, the classification of the registrations of individuals is complete while the classification for the other category is almost complete.

At July $18^{\text {th }} 2001$, WHOIS contained 52,401 entries referring to individuals: after correcting classification errors and eliminating registrants from other EU countries, 51356 entries for Italian registrant were included. This article illustrates for the analysis of the determinants of the adoption of an Internet domain name by individuals.

\section{RESULTS}

\subsection{ANALYSIS OF CONCENTRATION}

Only persons who are over 18 years old can register a domain under the ccTLD "it". The average age of registrants is quite low that is about 36 vs. about 49 , which is the average age of the whole population. The class 28-37 is the most represented. About $85 \%$ of registrants are male while the total number of males in the population is about $48 \%$. It seems that young people and males are more likely to register a domain. These data match the literature (Ingrassia, Comis and Mammana, 1995).

However, while a lot of surveys on samples of Internet users show the reduction of the gender gap for Web surfers, our data demonstrate that it is

\footnotetext{
${ }^{6}$ The Italian Registration Authority is at the Istituto di Informatica e Telematica of Consiglio Nazionale delle Ricerche (CNR), Area di Pisa.

${ }^{7}$ Whois database, database of the state of the registrations, database of the letters of assumption of responsibility (LAR).

${ }^{8}$ In order to classify data we are using a database of Italian firms managed by Infocamere.
} 
still present if we focus on an advanced and proactive use of the Internet network.

Italy is divided into 103 administrative units called provinces. The geographical distribution of domains is highly concentrated (Graph 1). The first three provinces, all including large cities (Rome, Milan, Naples) account for $29.1 \%$ of the total. The distribution of domains is much more concentrated than the distribution of the population: its Herfindahl index is 0.0418 vs. 0.0215 , which represents the population concentration; the Gini index is 0.567 vs. 0.429 . At the same time it is more concentrated than the distribution of the income: the Herfindahl is 0.025 and the Gini is 0.458 . The penetration rate

$\frac{\text { Number of domains }}{\text { Population over } 18}$

is between $0.3 \%$ and $0.03 \%$. The three provinces having the higher penetration are of medium size.

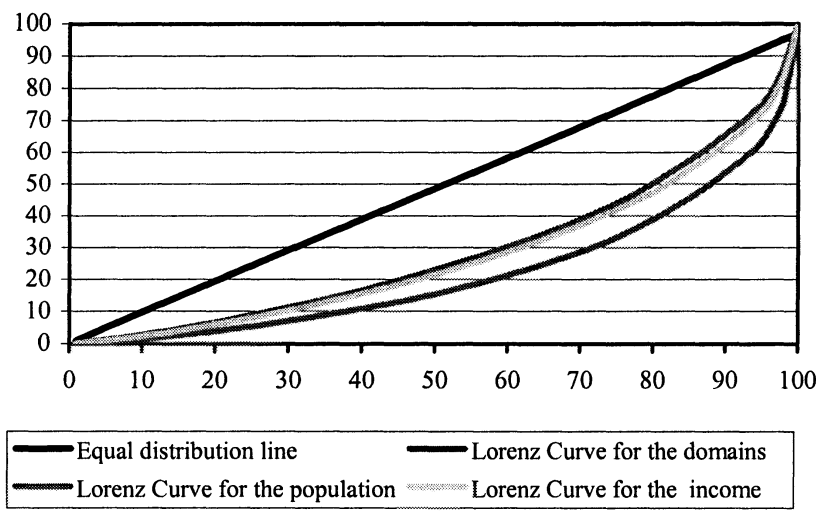

Graph 1: Lorenz Curves for domains, income and population. 


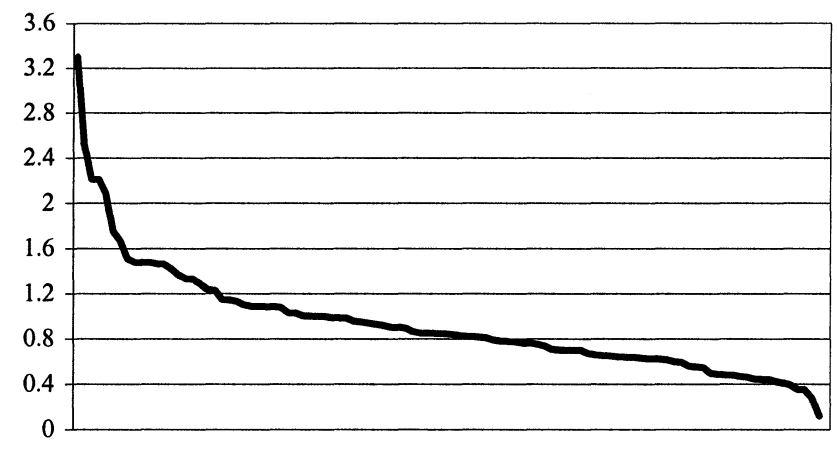

Penetration rates in the Italian provinces

Graph 2: Penetration rates of domains in different provinces.

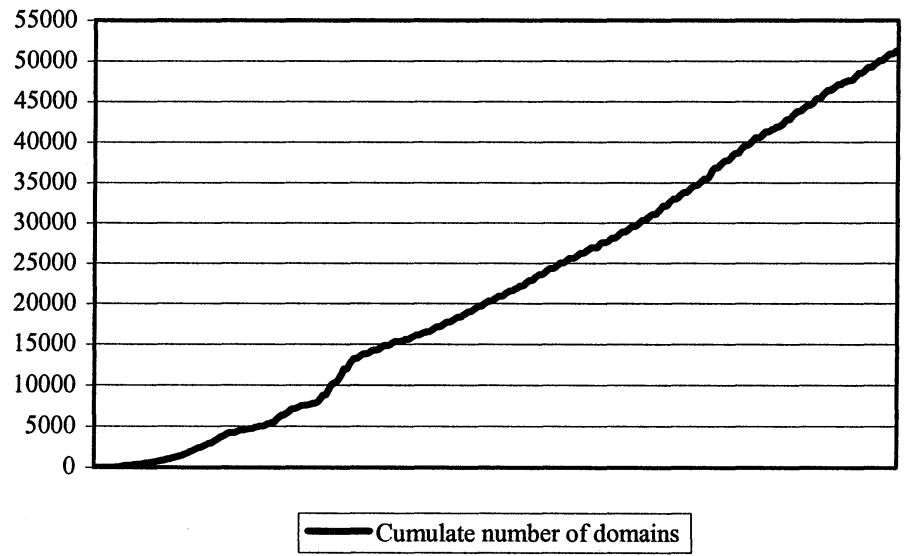

Graph 3: Cumulate number of domains registered by individuals.

Note: In Graph 2, Italian provinces are reported on the $x$-axis while in Graph 3 the cumulate number of domains is referred to the period from 15 January 2000 to 18 July 2001. According the rules of the Italian Registration Authority, individuals are allowed to register a domain starting from 15 January 2000. 
These findings shed light on the diffusive effect of Internet, i.e. the potential of the technology to reduce differences in the concentration of population (provinces with large urban concentrations vs. provinces with small cities) and concentration of income (rich provinces vs. poor ones). A diffusive effect could be justified by the decentralized, non-hierarchical, immaterial nature of the Internet technology, which in principle should not have strong barriers to entry as it happens in manufacturing. Data show that this effect does not take place at all at the aggregate level. Domains are even more concentrated than population and income. A ranking of provinces by penetration rate, not reported here, clearly shows that the distribution of Internet follows large differences in the level of income. Before drawing conclusions, these data should be compared to those on the use of domains by business firms, and this comparison is currently in progress. Our preliminary conclusion is that, far from being an "equalizer", Internet technology follows and possibly sharpens existing differences in economic opportunities, not only across countries, but even within industrialized countries.

\subsection{DETERMINANTS OF ADOPTION}

In order to analyse the factors leading to the registration of domains by individuals, we run exploratory stepwise regressions using indicators at the province level. The dependent variable is the absolute number of domains in the province (Table 1) and the penetration rate (Table 2). Models are kept compact by only using explanatory variables of the same kind. Independent variables are not normalized.

Regressions in Table 1 show that the number of domains depends on the number of employees in the service sector. Total disposable income has a negative, but very weak effect.

Adoption depends on the skills available in the province, approximated by the patents and the educational infrastructure. Interestingly, while patents are a significant factor, the manufacturing sector, which produces most patents, is not relevant as such, suggesting that only a portion of it is important for Internet adoption. 


\begin{tabular}{|c|c|c|c|c|c|c|c|}
\hline Variables & $\begin{array}{c}\text { M1: } \\
\text { Economics } \\
\text { Variables }\end{array}$ & $\begin{array}{l}\text { M2: Skill } \\
\text { Variables }\end{array}$ & $\begin{array}{c}\text { M3: } \\
\text { Social } \\
\text { Variables }\end{array}$ & $\begin{array}{c}\text { M4: } \\
\text { Demographic } \\
\text { Indicators }\end{array}$ & $\begin{array}{c}\text { M5: } \\
\text { Infrastructure } \\
\text { Indicators }\end{array}$ & $\begin{array}{l}\text { M6: Public } \\
\text { Expenditure }\end{array}$ & $\begin{array}{c}\text { M7: } \\
\text { Industrial } \\
\text { Demo- } \\
\text { graphy }\end{array}$ \\
\hline $\begin{array}{c}\text { Employees in service } \\
\text { sectors** }\end{array}$ & $\begin{array}{l}7.642 \\
(.631) \\
\end{array}$ & & & & & & \\
\hline $\begin{array}{c}\text { Employees in } \\
\text { agricultural } \\
\text { sectors** }\end{array}$ & $\begin{array}{l}-13.698 \\
(3.076)\end{array}$ & & & & & & \\
\hline $\begin{array}{l}\text { Total disposable } \\
\text { Income** }\end{array}$ & $\begin{array}{c}-1.735 \mathrm{E}-05 \\
(.000)\end{array}$ & & & & & & \\
\hline Number of patents** & & $\begin{array}{l}1.644 \\
(.141)\end{array}$ & & & & & \\
\hline $\begin{array}{c}\text { Educational } \\
\text { Infrastructure }\end{array}$ & & $\begin{array}{c}3.742 \\
(1.342) \\
\end{array}$ & & & & & \\
\hline $\begin{array}{l}\text { Expenditure for } \\
\text { movie theatres** }\end{array}$ & & & $\begin{array}{c}5.029 \mathrm{E}- \\
02 \\
(.005) \\
\end{array}$ & & & & \\
\hline $\begin{array}{l}\text { Expenditure for sport } \\
\text { events** }\end{array}$ & & & $\begin{array}{c}-5.845 \mathrm{E}- \\
03 \\
(.003) \\
\end{array}$ & & & & \\
\hline $\begin{array}{l}\text { Expenditure for } \\
\text { magazines** }\end{array}$ & & & $\begin{array}{c}-3.209 \mathrm{E}- \\
02 \\
(.010) \\
\end{array}$ & & & & \\
\hline $\begin{array}{l}\text { Expenditure for } \\
\text { newspapers* }\end{array}$ & & & $\begin{array}{c}8.468 \mathrm{E}- \\
03 \\
(.004) \\
\end{array}$ & & & & \\
\hline $\begin{array}{c}\text { Density of } \\
\text { population** }\end{array}$ & & & & $\begin{array}{c}3.051 \mathrm{E}-02 \\
(.001)\end{array}$ & & & \\
\hline $\begin{array}{l}\text { Number of foreign } \\
\text { residents** }\end{array}$ & & & & $\begin{array}{l}.309 \\
(.074)\end{array}$ & & & \\
\hline $\begin{array}{l}\text { Telecommunication } \\
\text { infrastructure** }\end{array}$ & & & & & $\begin{array}{l}12.915 \\
(1.778)\end{array}$ & & \\
\hline Port infrastructure** & & & & & $\begin{array}{r}-1.081 \\
(.282) \\
\end{array}$ & & \\
\hline $\begin{array}{c}\text { Cultural and } \\
\text { recreational } \\
\text { infrastructure** }\end{array}$ & & & & & $\begin{array}{c}3.378 \\
(1.145)\end{array}$ & & \\
\hline $\begin{array}{c}\text { Energy and } \\
\text { environmental } \\
\text { Infrastructure** }\end{array}$ & & & & & $\begin{array}{l}-5.356 \\
(1.863)\end{array}$ & & \\
\hline $\begin{array}{c}\text { Water and electrical } \\
\text { systems** }\end{array}$ & & & & & & $\begin{array}{c}1.399 \mathrm{E}-02 \\
(.003)\end{array}$ & \\
\hline Public housing** & & & & & & $\begin{array}{c}2.201 \mathrm{E}-02 \\
(.004)\end{array}$ & \\
\hline $\begin{array}{c}\text { Railroad and } \\
\text { transportation } \\
\text { works** }\end{array}$ & & & & & & $\begin{array}{l}2.628 \mathrm{E}-03 \\
(.001)\end{array}$ & \\
\hline $\begin{array}{c}\text { Road and airport } \\
\text { works** }\end{array}$ & & & & & & $\begin{array}{c}6.981 \mathrm{E}-03 \\
(.002)\end{array}$ & \\
\hline Housing** & & & & & & $\begin{array}{c}-2.160 \mathrm{E}-02 \\
(.008) \\
\end{array}$ & \\
\hline $\begin{array}{l}\text { Net increase in the } \\
\text { number of join stock } \\
\text { companies** }\end{array}$ & & & & & & & $\begin{array}{l}1.171 \\
(.036)\end{array}$ \\
\hline $\mathrm{R}^{2}$ & 0.958 & 0.641 & 0.953 & 0.946 & 0.517 & 0.748 & 0.912 \\
\hline
\end{tabular}

Table 1: Stepwise regressions with number of domains as dependent variable $\left(^{* *} P<0.01\right.$, ${ }^{*} P<0.05$, Standard error in parenthesis) 


\begin{tabular}{|c|c|c|c|c|c|}
\hline Variables & $\begin{array}{c}\text { M8: } \\
\text { Economics } \\
\text { Variables }\end{array}$ & $\begin{array}{l}\text { M9: Skill } \\
\text { Variables }\end{array}$ & $\begin{array}{c}\text { M10: } \\
\text { Social } \\
\text { Variables }\end{array}$ & $\begin{array}{c}\text { M11: } \\
\text { Demographic } \\
\text { Indicators }\end{array}$ & $\begin{array}{c}\text { M12: } \\
\text { Infrastructure } \\
\text { Indicators }\end{array}$ \\
\hline $\begin{array}{c}\text { Employees in service } \\
\text { sectors** }\end{array}$ & $\begin{array}{c}3.374 \mathrm{E}-05 \\
(.000) \\
\end{array}$ & & & & \\
\hline $\begin{array}{l}\text { Per capita disposable } \\
\text { income* }\end{array}$ & $\begin{array}{c}1.144 \mathrm{E}-03 \\
(.000)\end{array}$ & & & & \\
\hline Per capita patents** & & $\begin{array}{c}7.922 \mathrm{E}-04 \\
(.000)\end{array}$ & & & \\
\hline $\begin{array}{c}\text { Rate of enrolment to } \\
\text { high schools (females)* }\end{array}$ & & $\begin{array}{c}1.061 \mathrm{E}-05 \\
(.000)\end{array}$ & & & \\
\hline $\begin{array}{c}\text { Theatre and musical } \\
\text { expenditure** }\end{array}$ & & & $\begin{array}{c}2.395 \mathrm{E}-06 \\
(.000)\end{array}$ & & \\
\hline $\begin{array}{c}\text { Number of foreigners } \\
\text { every } 1,000 \\
\text { inhabitants** }\end{array}$ & & & & $\begin{array}{l}2.971 \mathrm{E}-05 \\
(.000)\end{array}$ & \\
\hline $\begin{array}{c}\text { Banking and service } \\
\text { infrastructure** }\end{array}$ & & & & & $\begin{array}{l}9.238 \mathrm{E}-06 \\
(.000)\end{array}$ \\
\hline $\begin{array}{c}\text { Energy and } \\
\text { environmental } \\
\text { infrastructure** }\end{array}$ & & & & & $\begin{array}{l}-3.691 \mathrm{E}-06 \\
(.000)\end{array}$ \\
\hline Port infrastructure** & & & & & $\begin{array}{c}-4.086 \mathrm{E}-07 \\
(.000) \\
\end{array}$ \\
\hline $\mathrm{R}^{2}$ & 0.265 & 0.141 & 0.254 & 0.278 & 0.304 \\
\hline
\end{tabular}

Table 2: Stepwise regressions with penetration rate as dependent variable ${ }^{* *} P<0.01$, $* P<0.05$, Standard errors in parenthesis)

Adoption also depends on cultural expenditure of higher quality (theatres and newspapers), while it seems to substitute for sports events and magazines. Internet is adopted more in densely populated provinces that are open to foreign residents. As expected, it is also more adopted in provinces with a larger telecommunication infrastructure, while other heavier infrastructures (energy and ports) have a negative impact. Again, cultural infrastructure is important.

Public expenditure in material infrastructures (water, road, railroad, airport, public housing) is also highly significant. Interestingly enough, Internet does not abolish the need for material infrastructure at local level. Finally, the net increase in limited liability companies is also relevant, while the net increase in simpler types of firms is not significant.

Models using the penetration rate as a dependent variable basically confirm this picture (Table 2).

Provinces that are densely populated, tertiary, highly schooled and skilled, culturally open and internationalised, with adequate endowments of infrastructure and an advanced entrepreneurial environment are the best candidates for a more active and interactive use of the Internet.

The main problem of the models presented above is multicollinearity. Stepwise regression eliminates strong correlated variables: all variables must 
pass a tolerance ${ }^{9}$ criterion (tolerance level 0.0001 ) to be entered in the model and a variable is not entered if it caused the tolerance of another variable already in the model to drop below the tolerance criterion. Anyway, an analysis of variance and covariance matrices is necessary. Let's start with the models having domains as a dependent variable.

\section{FURTHER DEVELOPMENTS OF THE RESEARCH}

\subsection{ANALYSIS OF REGISTRATIONS BY FIRMS}

At the present, we are constructing the database containing domains registered by firms. The naming rules established by the Italian Naming Authority ${ }^{10}$, state that individuals can only register one domain name. This restriction does not apply to firms.

For each firm that has registered a domain, our database will report the date of registration, the name of the firm, its province of location and its legal form. Particular attention is paid to the distinction between entrepreneurs and companies.

This database will allow to study the determinants of the adoption of domains by firms and then the pattern of diffusion of this technology in the Italian production system. On one hand, we will perform regressions by using indicators at the province level, on the other hand we will construct a sample of firms for which data on structural characteristics (with particular attention to the size) will be collected in order to test their influence on adoption. Moreover, given that we have the time series of the registrations starting from the early Ninety, we will estimate the hazard rates testing also for the presence of network externality phenomena. The idea is to test if the rate of diffusion in $t+1$ depends on the rate of diffusion in $t$.

\subsection{THE DISTRIBUTION OF DOMAIN NAMES}

At the present a growing body of literature is devoted to discover and analyse the regularities displayed by the Internet network (Pitkow, 1998). In particular, the presence of power laws (Blank, Solomon, 2000) for Internet related phenomena is widely accepted.

\footnotetext{
9 Tolerance: A statistic used to determine how much the independent variables are linearly related to another (multicollinear).

${ }^{10}$ Naming rules are available at http://www.nic.it/NA/index-engl.html.
} 
Power laws are discovered in the number of in and out links of a web site (Barabasi, Albert, 1999; Adamic, Huberman, 2000), in the number of pages composing an Internet web site, in the behaviour of Internet surfers (Huberman, Pirollo, Pitkow, Lukose, 1998; Johansen, 2001).

Among the several types of power laws that have been detected, Zipf's law (Zipf, 1949) seems to play a central role. This law has been especially applied to the analysis of the distribution of the population of cities in a country or in a region (Gabaix, 1999; Krugman, 1996, 1998). Under this law if you order cities according to population and plot in a graph the logarithm of the population against the logarithm of the rank, you obtain a straight line whose slope is about -1 . So it is possible to say that the population of the first city in a country is approximately twice as much as the population of the second city, three times as much as that of the third city and so on.

Moreover, this seems to be a wide general law that has been applied in linguistics (for the frequency of words in a text, Mandelbrot, 1965; Alexander, Sidorov, 2001), in the study of the intensity of earthquakes (Sonette et al., 1996) and in several fields of biology and physiology (Jorgensen, Mejer and Nielsen, 2001). In economics it has been applied to the distribution of firm sizes (Axtell, 2001), measured in different ways (income, assets, number of employees) (Okuyama, Takayasu, Takayasu, 1999).

The idea is then to investigate the presence of power laws for domains registered by individuals in Italian cities and later for domains registered by firms and other organisations, looking for the presence of a rank size rule governing the number of registered domains. If a power law is discovered, the challenge will be to analyse how it is generated. In fact, at the present there is not any generally accepted theoretical foundation for this empirical regularity.

\section{REFERENCES}

[1] Adamic L., Huberman B. (1999) Growth dynamics of the World Wide Web. Nature, 401, page 131.

[2] Albert L., Barabasi, R. A. (1999) Emergence of scaling in random networks. Science, 286(5439) pages 509-512.

[3] Alexander G., Sidorov G. (2001). Zipf and Heaps laws' coefficients depend on language. Proceeding of Conference on Intelligent Text Processing and Computational Linguistics (CICLing'2001), ed. Alexander Gelbukh, Lecture Notes in Computer Science, Vol. 2004 (Springer-Verlag), pages 332-335.

[4] Axtel R. (2001) Zipf distribution of U.S. Firm Sizes. Science, 293, pages 1818-1820.

[5] Blank A., Solomon S. (2000) Power laws in cities population, financial markets and Internet site (scaling in systems with variable number of components). Physica A, 287, pages 279-288. 
[6] Coffman K.G. and Odlyzko A.M. (2001). Internet growth. AT\&T Labs report.

[7]Diez-Picazo G.F. (1999) An Analysis of International Internet Diffusion. Ph.D. Thesis, MIT.

[8]Fujita M., Krugman P., Venables A. (1998) The spatial economy. MIT press, Massachusetts.

[9] Gabaix X. (1999) Zipf's Law for cities: an explanation. Quarterly Journal of Economics, pages 739-767.

[10] Ingrassia S., Comis E., Mammana M. (1995). Internet in Italia-Un'indagine statistica. Università degli Studi di Catania

[11] Johansen A. (2001) Response time of Internauts. Physica A, 296, pages 539-546

[12] Jorgensen S., Mejer H., Nielsen S. (2001) Ecosystem as a self-organizing critical system. Ecological Modelling, 111, pages 261-268.

[13] Krugman (1996) The self-organizing economy. Blackwell, Mandell

[14] Mandelbrot B. (1965) Information theory and psycholinguistics. In Scientific Psychology: Principles and Approaches, eds. B. Wolman, E. Nagel (Basic, Books, 1965), pages 550-562.

[15] Naldi M. (1997). Size estimation and growth forecast of the Internet. Centro Volterra, Tor Vergata

[16] OECD (1998) Internet infrastructure indicators. OECD report.

[17] Okuyama K., Takayasu M, Takayasu, H. (1999) Zipf law in income distribution of companies Physica A, 269,pages 125-131.

[18] Sornette D., Knopoff L., Kagan Y., Vanneste C. (1996) Rank-ordering statistics of extreme events: application to the distribution of large earthquakes. Journal of Geophysical Research, 101, pages 13883-13894.

[19] Zipf K.G. (1949) Human Behaviour and the principle of least effort. Addison-Wesley, Cambridge, Massachusetts.

[20] Zook M.A. (1999). The Web of Consumption: Spatial Organisation of the Internet Industry in the United States. American Behavioural Scientist (forthcoming). 